\title{
(6) OPEN ACCESS \\ Ethics of genetic testing and research in sport: a position statement from the Australian Institute of Sport
}

\author{
Nicole Vlahovich, ${ }^{1,2}$ Peter A Fricker, ${ }^{3}$ Matthew A Brown, ${ }^{4}$ David Hughes ${ }^{1}$
}

${ }^{1}$ Department of Sports Medicine, Australian Institute of Sport, Bruce, Australian Capital Territory, Australia ${ }^{2}$ CRN for Advancing Exercise and Sport Science, Bond University, University Drive, Robina, Queensland, Australia ${ }^{3}$ Research Institute for Sport and Exercise, University of Canberra, University Drive, Bruce, Australian Capital Territory, Australia ${ }^{4}$ Institute of Health and Biomedical Innovation, Queensland University of Technology, Translational Research Institute, Princess Alexandra Hospital, Brisbane, Queensland, Australia

\section{Correspondence to} Dr David Hughes, Department of Sports Medicine, Australian Institute of Sport, Bruce, ACT 2617, Australia; david. hughes@ausport.gov.au

Accepted 7 November 2016 Published Online First 29 November 2016

\section{CrossMark}

\section{To cite: Vlahovich $\mathrm{N}$,} Fricker PA, Brown MA, et al. Br J Sports Med 2017;51: 5-11.

\section{ABSTRACT}

As Australia's peak high-performance sport agency, the Australian Institute of Sport (AIS) has developed this position statement to address the implications of recent advances in the field of genetics and the ramifications for the health and well-being of athletes. Genetic testing has proven of value in the practice of clinical medicine. There are, however, currently no scientific grounds for the use of genetic testing for athletic performance improvement, sport selection or talent identification. Athletes and coaches should be discouraged from using direct-to-consumer genetic testing because of its lack of validation and replicability and the lack of involvement of a medical practitioner in the process. The transfer of genetic material or genetic modification of cells for performance enhancement is gene doping and should not be used on athletes. There are, however, valid roles for genetic research and the AIS supports genetic research which aims to enhance understanding of athlete susceptibility to injury or illness. Genetic research is only to be conducted after careful consideration of a range of ethical concerns which include the provision of adequate informed consent. The AIS is committed to providing leadership in delivering an ethical framework that protects the well-being of athletes and the integrity of sport, in the rapidly changing world of genomic science.

\section{INTRODUCTION}

Genomics is the study of the structure, function, evolution and mapping of genomes. There have been huge advances in the field of genomics over the past decade. Rapidly evolving knowledge and technologies have led to wider use and availability of genetic testing, greatly reduced costs of DNA sequencing and significantly reduced reporting times on genetic tests. There has been a surge in genetic research across all medical specialties and enhanced understanding of the impact of genetics on the health of individuals. There is currently a relative paucity of quality genetic research in sport and exercise medicine but this will change rapidly over the coming decade. Inevitably, genetic testing will become commonplace in all fields of health science, including sport and exercise medicine.

It has been over 10 years since the human genome was mapped. In this time, the cost of sequencing a human genome has reduced dramatically, from US $\$ 2.7$ billion for the initial human genome project to <US\$1000 in $2015 .{ }^{1}$ The wealth of information and cost reduction has delivered a range of genetic research and testing options. Private companies are now offering direct-to-consumer tests within the marketplace, often with no involvement of a medical practitioner or genetic counselling.

Genetic research and testing is increasingly playing an important role in a range of medical fields. As a result, various position statements have been developed in relation to the management of genetic research and testing (Australian Medical Association (AMA), ${ }^{2}$ Association of Genetic Nurses and Counsellors (UK and Ireland) ${ }^{3}$ and National Human Genome Research Institute (US) ${ }^{4}$ ). The issue of genetic testing and research in sport has been previously addressed by Sports Medicine Australia, ${ }^{5}$ The British Association of Sport and Exercise Sciences ${ }^{6}$ and the Human Genetics Society of Australasia. ${ }^{7}$

The Australian Institute of Sport (AIS) is Australia's peak high-performance sport agency. The AIS is committed to ensuring that genetic testing and research in Australian sport is conducted with adherence to highest standards of evidence-based scientific practice. The AIS will lead in defining an ethical framework which informs the conduct of genetic testing and genetic research, and its applications in sport, while preserving principles of integrity, non-discrimination, privacy and confidentiality. This statement provides a detailed position on the current state of play, and guidance on the areas of focus for the future in this area. It outlines the AIS position on the ethics of genetic testing and research in Australian sport and states a number of positions that the AIS has adopted in this area.

\section{GENETIC TESTING FOR HEALTH-RELATED PURPOSES}

Genetic testing for health-related purposes is becoming increasingly common in the practice of medicine. Examples of commonly conducted medical genetic tests include HLA-B27 which is strongly associated with ankylosing spondylitis and other inflammatory diseases, ${ }^{8} \mathrm{C} 282 \mathrm{Y}$ and/or H63D for haemochromatosis ${ }^{9}$ and BRCA1 and BRCA2 for ovarian and breast cancer. ${ }^{10}$

Some genetic disorders do confer a known, significant health risk for individuals undertaking strenuous activity. For example, Marfan syndrome is an inherited connective tissue disorder associated with ocular, musculoskeletal and cardiovascular manifestations, characterised by a tall and slender build and disproportionately long limbs, posing potential lethal threat during high-intensity exercise. ${ }^{11}$ Marfan syndrome results most commonly from mutations in the fibrillin-1 (FBN1) gene on 
chromosome 15 , which encodes for the glycoprotein fibrillin. ${ }^{12}$ Sporting organisations such as professional basketball and volleyball associations should consider the possibility of Marfan syndrome when conducting preparticipation screening. When one or more of family history, symptom history, physical examination or diagnostic investigations (slit lamp ocular examination, echocardiogram) raise a suspicion of Marfan syndrome, molecular studies of the fibrillin gene may be useful in clarifying the diagnosis.

As with all medical investigations, genetic testing should only be performed where clinically indicated by the medical history and physical examination. The medical practitioner should ensure that appropriate counselling takes place prior to conducting genetic testing. The patient needs to be fully informed of the purpose of genetic testing, the possible results of the tests, the ramifications that the results could have for the patient and the potential ramifications that the results could have for the patient's family.

As is the case with many novel scientific advances, the rapid knowledge growth in human genomics has been associated with significantly reduced costs of genetic testing and increased availability of genetic testing to consumers. There has been a rapid expansion of direct-to-consumer services, with those services being provided to members of the public on a commercial basis without any involvement of a medical practitioner. ${ }^{13}$ Some countries have legislation which ensures that genetic testing cannot be carried out without the involvement of a medical practitioner while other countries have no such legislated protection for consumers. ${ }^{14}$ The claims of direct-to-consumer genetic testing websites in relation to sport performance are concerning as they are largely without scientific foundation. ${ }^{13} \mathrm{It}$ has been established that, currently, the evidence to support the provision of sports training nutritional advice based on genetic data is extremely weak. ${ }^{13}$ It is not appropriate for genetic testing to be conducted unless the results of such testing are subsequently interpreted by a medical practitioner with knowledge and skills to communicate the results accurately and provide evidence-based health advice to the patient. There is concern about consistency and quality control regarding reported results from direct-to-consumer genetic testing companies. A report in the USA from the Government Accountability Office indicated that genetic samples sent from the one individual to different direct-to-consumer companies resulted in inconsistent reporting between companies, including conflicting risk predictions for a range of diseases. ${ }^{15}$

Athletes and coaches are understandably focussed on implementing nutritional and training strategies in order to optimise exercise performance. For this reason, athletes and coaches may be vulnerable to the allure of direct-to-consumer genetic testing in the belief that the results of such testing will contribute to improved performance outcomes. The provision of inaccurate or non-evidence-based advice could potentially be harmful to the health of athletes.

\section{INVOLVEMENT OF ATHLETES IN GENETIC OR GENOMIC RESEARCH}

Genomic research raises a number of important issues for researchers, including the complexity of informed consent, sample and data storage, return of results, research involving children and privacy and confidentiality. ${ }^{4}$ Genetic discoveries are often difficult to translate into clinical practice. There are complexities in determining which gene variants are associated with increased risk, which have no impact on exposure to risk and whether an increase in disease risk (eg, from 15\% to 16\%) is clinically meaningful. For this reason, genetic studies require large numbers of participants and significant amounts of data to provide meaningful translation into clinical practice. The large amounts of data generated via genome-wide association studies (GWAS) and genome-wide sequencing (GWS) can often present a complex and confusing picture, only interpretable by genomics experts. Australia's National Health and Medical Research Council (NHMRC) has released a document that sets a standard for the translation of genomic (and other 'omics') research into practice: Principles for the translation of 'omics'-based tests from discovery to healthcare. ${ }^{16}$ Detailed by the NHMRC are four operational principles that apply to the translation of genomic discoveries into healthcare; reproducibility, collaboration, education and interoperability. A framework for considering these principles is presented, with the key domains detailed for the translation of research discoveries into clinical care. The four domains; test discovery and analytical validation, clinical validation, healthcare and data management provide researchers with the key issues to address and consider throughout the translation of research into the development of an 'omics' test. ${ }^{16}$ These principles and domains must be considered when developing, using and refining genomic techniques on athletes.

In Australia, the genetic testing of humans for the purposes of research is governed by the National Statement on Ethical Conduct in Human Research 2007 (the National Statement), which was developed jointly by the NHMRC, the Australian Research Council and Universities Australia. ${ }^{17}$ Similarly, genetic testing of humans for the purposes of research is guided internationally by a range of national bodies including the National Institutes of Health ${ }^{18}$ and the Food and Drug Administration ${ }^{19}$ (USA), The Canadian College of Medical Geneticists ${ }^{20}$ (Canada) and the Medical Research Council ${ }^{21}$ (UK). The National Statement dedicates a chapter to studies of human genetics, providing a range of ethical considerations to be taken into account when designing research involving genetic testing. As with all human research, genetic research compels research institutions to accept responsibility for establishing procedures for the ethical review of the proposed research. The ethical concerns surrounding genetic research in other fields of human health apply equally to genetic research involving elite and recreational athletes.

In all areas of medical and scientific research, it is critical that potential research participants are fully informed of the nature of the research, the potential risks of being involved in the research and the hoped-for benefits of successfully completing the research. Genomics is a new field of research and the language used in this field is unfamiliar to most. Informed consent remains a major concern for the inclusion of participants in genetic research. $^{22} 23$ Where there is any lack of comprehension or confusion regarding terms or language used, there is potential for failure of appropriate informed consent. Potential barriers to informed consent include language that is vague and variable, words with both technical and common meanings, novel phrases without clear meaning, a lack of definitions and common concepts that assume new definitions in genetics research. Language gaps between researcher and potential research participants may unintentionally impair comprehension and ultimately impair informed consent in genomic research. ${ }^{24}$ The purposes for which genetic information will be used must be clearly articulated in plain language. Researchers should 'road test' consent forms on athletes to validate athlete comprehension of the subject matter.

Certain types of genetic research involve the possibility of unintentional detection of a genetic mutation associated with increased incidence of serious disease for the participants or 
their relatives. ${ }^{25}$ There needs to be a clear prospective agreement with the patient about how such discoveries will be managed, should the situation arise. Where genetic tests are performed for research purposes, the ethics approval process must take into account the potential for adverse discoveries and how these are managed.

In research specifically involving elite athletes, it is important to ensure that the willingness to participate is attributed to the athlete themselves and not a coach or sporting organisation with which the athlete may have a unique relationship. The National Statement provides guidance on the consent process for 'people in dependent or unequal relationships'. ${ }^{17}$ Teachers and students are used as a specific example of a situation where an individual may feel compelled or coerced to participate. A similar situation could arguably exist in the relationship between governing sport bodies, coaches and athletes. The relationship between coach and athlete is unique. ${ }^{26} 27$ The role of the governing body/coach in the athlete's decision to participate, therefore, requires careful consideration. This is not to say that the governing body/coach should not provide support or advice in the decision to participate, but it 'constitutes a reason to pay particular attention to the process through which consent is negotiated'. ${ }^{17}$ Ethically, the athlete must be given the choice to participate or decline research participation. The decision of an athlete to decline participation in genetic research should be respected and no discrimination or penalty should be imposed on the athlete for this decision. Where the researchers are also service providers, the decision to decline participation should not impact on the provision of services to the athlete. Similarly, where the researchers are providing services to the athlete, great care must be taken to ensure that athletes do not feel that they are in debt to the clinician/researcher and thereby feel an obligation to participate.

Privacy of genetic information is of critical importance for ethical practice. The AMA recommends that 'genetic information acquired in the context of the doctor-patient relationship should not be disclosed to a third party without the patient's specific, and where possible, written consent, unless undertaken in accordance with relevant privacy legislation'. ${ }^{2}$ A third party in the context of sport may include a coach, trainer or sports administrator. It is currently common practice for athletes to sign a waiver of medical confidentiality when entering an elite or professional sports programme. Such a waiver allows medical personnel to share the athlete's medical information with coaching and non-medical support staff in situations where the medical condition impacts on training or competition participation. Usually, there are exceptions built into such arrangements where the medical information is of a particularly sensitive nature. Confidentiality clauses pertaining to results of genetic testing must be clearly articulated when obtaining informed consent from an athlete in relation to genetic testing results. In the absence of specific agreement to the sharing of genetic results, these results must remain confidential.

The inclusion of children in genetic research raises additional ethical concerns. The National Statement describes a number of issues with inclusion of minors in research, including a reduced capacity to understand what the research entails and its future impacts, and the potential for coercion into participation by parents or others. ${ }^{17}$ According to the AMA 'children should not normally undergo predictive genetic testing until they have reached the age of consent and so are able to request the test on their own behalf'. ${ }^{2}$ The American Society of Human Genetics (ASHG) states that children warrant special consideration for several reasons, including their lack of decision-making capacity. ${ }^{28}$ While the National Statement and guidance from the ASHG provide measures to allow inclusion of children in genetic research, the inclusion of a child should be in the child's 'best interest' and defining this for an individual child is often complex and controversial. ${ }^{28}$ The inclusion of minors in some studies may be highly desirable, particularly when the research involves childhood disease. Research where the desired participants include elite athletes is unlikely to involve investigation into serious conditions that exclusively effect minors. It is therefore recommended that athletes under the age of 18 years are precluded from these studies.

The National Statement also deals with the issue of withdrawal of consent. It is stated that 'participants are entitled to withdraw from the research at any stage. Before consenting to involvement in the research, participants should be informed about any consequences of such withdrawal'. ${ }^{17}$ In the case of athlete participation in genetic research, there should be no negative consequences from withdrawing consent to a research study. It is possible that athletes may become upset or distressed as a result of their participation in the research. Athletes should have the right to withdraw from the study and ask that their information and samples are destroyed. Where the researchers are also service providers, a decision to withdraw from research participation should not impact negatively on the provision of services to the athlete or the relationship between the service provider and the athlete. Genetic information and material, like other medical information or material, is the property of the patient. As such, the patient has a right to access such information and furthermore has a right to request that the information is shared with a third party.

The ramifications of the mode of the sample collection should also be taken into account when involving athletes in genetic research. When studying genetic variation, or DNA gene sequences, it advisable that the least invasive method is used to collect samples for DNA analysis. Saliva samples should be considered for use in place of blood samples or muscle biopsies, where such a sample technique does not compromise the objectives of the research. When designing a study involving elite athletes, sample collection technique may require extra consideration. For example, there is a high level of interest regarding gene expression determinants of muscle type in elite athletes. Consideration must therefore be given where invasive techniques such as muscle biopsy may potentially affect athlete performance or preparation for events.

\section{GENETIC RESEARCH AND GENE DOPING}

Gene therapy has shown some promise in the treatment of specific diseases in the controlled environment of a clinical trial. ${ }^{29}$ It is feasible that the same technologies will be adopted by athletes seeking methods for enhancing athletic performance. Evolving knowledge in the field of genetic research has the potential to be used in sport, creating a new form of doping known as gene doping. ${ }^{30}$

Gene or cell doping is defined by the World Anti-Doping Agency (WADA) as 'the non-therapeutic use of genes, genetic elements and/or cells that have the capacity to enhance athletic performance'. The 2015 Prohibited List states, 'The following, with the potential to enhance sport performance, are prohibited:

1. the transfer of polymers of nucleic acids or nucleic acid analogues;

2. the use of normal or genetically modified cells'. ${ }^{31}$

The use of gene therapy is still in its infancy and has been shown to have a number of risks attached to it, including 
immune system reactions, targeting of the gene to the wrong cells/sequences and the possibility of causing tumours or malignancies. ${ }^{29}$ In the case of using gene therapy to treat serious conditions, the benefits of treatment often outweigh the risks. The use of genetic modification in the attempt to improve sporting performance, however, is unlikely to confer such a favourable benefit to risk ratio. It is unethical to attempt genetic modification on elite athletes with the aim of achieving performance gains. Genetic modification for this purpose is also unsafe, given the lack of any appropriate clinical trials of such procedures. This practice is prohibited and gene doping should not be used on elite or aspiring athletes.

The threat of gene doping should not be used as a reason to prevent ethical and legitimate research which has the potential to deliver health benefits to the wider, non-athletic community. Ethical genetic research in the field of sport and exercise medicine has the potential for developing strategies for the detection of gene doping, promoting legitimate researchers as being proactive in the fight against doping.

\section{ETHICS OF GENETIC RESEARCH AND TESTING TARGETING TALENT IDENTIFICATION}

High-performance sport is, by its nature, a competitive environment. A great deal of effort is directed into strategies to provide athletes with a performance 'edge', relative to their competitors. As the science of genomics progresses, there is increasing interest in the role that genetic testing might play in identifying individuals with genetic characteristics which might be advantageous in the sporting environment.

Two genes are primarily referred to in relation to sports performance; the gene for angiotensin I-converting enzyme (ACE) and the gene for $\alpha$-actinin-3 (ACTN3). The ACE gene was the first to be widely recognised in its association with performance, with a polymorphism shown to be related to improvements in performance and exercise duration in a variety of populations. $^{32} 33$ The I allele, which represents an insertion of $287-\mathrm{bp}$, is associated with improved performance in endurance sports while the deleted form of the variant is associated with enhanced performance in sports requiring sprinting or short bursts of power. The ACTN3 R577X polymorphism represents a base change within the ACTN3 gene that results in a premature stop codon and a deficiency in $\alpha$-actinin- 3 protein. Research conducted in 2003 demonstrated a link between ACTN3 and athletic abilities, showing that male and female elite sprint athletes have significantly lower frequencies of the $577 \mathrm{X}$ allele, compared with controls, indicating that $\alpha$-actinin- 3 protein could be a key factor for success as a power athlete. ${ }^{34}$ Additionally, endurance athletes have a higher frequency of the $577 \mathrm{X}$ allele, leading to a deficiency in $\alpha$-actinin- 3 protein that may be beneficial for endurance activity. This study, replicated through many subsequent studies, ${ }^{35}$ has led to the suggestion that an individual is inherently predisposed towards specialised performance in either sprint/power or endurance activity. ${ }^{34}$

Further research has consistently supported the view that the genotypes of $A C E$ and ACTN3 influence human performance in relation to sprint/power or endurance events. A systematic review and meta-analysis of the literature ${ }^{36}$ concluded that there is 'solid evidence for the associations between ACE II genotype and endurance events and between ACTN3 $\mathrm{R}$ allele and power events'. Despite the correlation between some genes and elite athletic performance, there is no scientific evidence for the predictive value of genetic profiling in sports performance. Examining genetic profiles alone cannot currently reliably predict athletic performance. ${ }^{37}$ The majority of sports have a combination of sprint/power and endurance components together with many other factors, including a broad variety of genetic, physical, environmental and psychological elements. Genetic attributes are only one of many contributing factors to athletic success.

Several commercial entities now offer 'predictions' on athletic ability using direct-to-consumer genetic testing. Direct-to-consumer testing that provides analysis of genes in association with sports performance and sports talent is primarily based around $A C E$ and $A C T N 3$. Each company differs, however, in the additional genes that are examined within a commercial test. There are several concerns about the effect of genetic testing on individual athletes using direct-to-consumer testing, particularly when this involves children. ${ }^{13}$ The lack of evidence-based interpretation of test results may result in (aspiring) athletes being provided with inappropriate advice about their suitability for specific sporting activities. Inappropriate advice could in turn be detrimental to the physical or psychological health of an individual. In a review of the use of genetic analysis in talent identification, Pitsiladis states, 'Current genetic testing has zero predictive power on talent identification and should not be used by sporting organisations, athletes, coaches or parents'. ${ }^{38}$ Use of genetic phenotypes as an absolute predictor of athletic prowess or sport selection is unscientific and unethical. The use of these tests in young athletes is particularly problematic as results may be incorrectly interpreted and provide limitations to children's possible choices of potential activities. ${ }^{39}$ Given the multifactorial nature of human athletic performance, information gained from genetic testing should never be used for inclusion or exclusion in talent identification.

Genomic research in relation to performance is a new field of medical science, unfamiliar to all but a few highly specialised scientists and medical practitioners. Misinterpretation of data is a real risk. Studies of the genomics of sport performance have been underpowered and are prone to type I statistical error, where an effect is stated to be a significant outcome when the reality is that it has occurred simply by chance. ${ }^{38}$ Australian government legislation exists to protect the public in relation to therapeutic goods via the Therapeutic Goods Act (1989). The legislation applies a risk management approach designed to ensure therapeutic goods supplied in Australia meet acceptable standards of quality, safety and efficacy (performance). The Therapeutic Goods (Excluded purposes) Specification 2010, 4 (2)(b), excludes the entry of in vitro diagnostic medical devices (IVDs) for self-testing onto the Australian Register of Therapeutic Goods (ARTG) where the purpose is genetic testing to determine the presence of, or predict susceptibility to, diseases in humans. ${ }^{40}$ Direct-to-consumer companies, however, continue to specifically target athletes and non-medical health professionals in Australia by providing interpretation of genetic testing results and related advice directly to customers. Such advice seeks to sidestep government legislation by avoiding mention of medical diseases, while providing advice on a range of sport-related matters including nutrition, power-sport potential, cardiofitness potential, injury risk, talent identification and psychological aptitude. The evidence underpinning such advice is weak or non-existent. There is no requirement for involvement of a medical practitioner in the provision of such advice. Direct-to-consumer genetic testing should be discouraged as there is high risk of misinterpretation of data, especially when there is no involvement of a skilled medical practitioner or counsellor in the process. ${ }^{13}$

The Australian Law Reform Commission and the NHMRC through the 2003 Essentially Yours report recommended that 'discrimination laws should be amended to clearly prohibit 
unlawful discrimination based on a person's real or perceived genetic status'. ${ }^{41}$ This type of discrimination is dealt with in existing Commonwealth, state and territory antidiscrimination laws. Potentially, any of the grounds or attributes listed in Australian antidiscrimination law may be relevant to discrimination on the basis of genetic status. Extending this premise to sport indicates that the knowledge of an athlete's genetic make-up cannot be used to exclude that athlete from selection for a particular programme or team. It is also unethical to use genetic testing for positive discrimination, for example, including an athlete in a team or programme.

\section{ETHICS OF GENETIC RESEARCH AND TESTING IN RELATION TO INJURY}

Injuries to athletes are common. Each sport has its own sport-specific injury risk profile. Comprehensive injury surveillance is performed by many professional sporting bodies to shed light on the impact of particular injuries. The international body for football, FIFA, has systematically surveyed football injuries in their tournaments since 1998 and reports an injury rate of 2.6 injuries per match played. ${ }^{42}$ Analysis of the London Olympic Games found that $11 \%$ of athletes reported an injury during the Games. ${ }^{43}$ The overall incidence of running-related lower limb injuries has been reported from $19.4 \%$ to $79.3 \%$, with $\sim 5 \%$ of active sport participants sustaining an injury in a 2 -week study period. ${ }^{44}$ In a systematic review of the literature, the most common injuries sustained by long-distance runners were found to be Achilles tendinopathy, Iliotibial Band (Friction) Syndrome (ITBS) and Medial Tibial Stress Syndrome (MTSS). ${ }^{45}$ At the elite level, these exercise-induced injuries are common and can stop athletes from training and competing, limiting the progress of athletes in top level competition. ${ }^{46}$ Sporting success at the international level is significantly impaired by loss of training and competition through injury (or illness) in the lead up to major events. ${ }^{47}$

The elite sport sector prioritises research that examines new approaches to reducing the number of training days lost through injury or illness. Similarly, research that has the potential to improve management of injury or illness is of great interest to sport administrators. Identification of genetic factors predisposing athletes to injury will allow coaches to customise training loads for individuals. Clinicians will be able to administer preventive, evidence-based interventions to reduce athlete injury.

A number of studies have demonstrated links between genetic variants and the risk of sports-induced injuries. Published genetic studies of exercise-induced injuries primarily focus on soft tissue injuries. ${ }^{48}$ In contrast, there are very few studies demonstrating the association between genetic polymorphisms and increased risk of bone stress injuries. ${ }^{49}{ }^{50}$ In the case of tendon injuries, genetic risk factors have been identified that correlate with increased risk of, or protection from, injury. ${ }^{51}$ Several genetic markers located within genes encoding for tendon structural proteins, extracellular proteinases and signalling molecules have been shown to be associated with chronic Achilles tendinopathy, and possibly Achilles tendon rupture. ${ }^{52}$ Genetic variation has also been shown to influence the risk of anterior cruciate ligament (ACL) tears in female athletes. ${ }^{53}$ The sample sizes of these studies have been quite small and it has been acknowledged that further investigation is required to replicate and correctly interpret the association of identified polymorphisms with specific injuries. ${ }^{51}$ Such studies should also be repeated in other populations, including non-Caucasian populations. ${ }^{52}$

All medical testing, including genetic testing, should only be undertaken with the consent of the individual. The AMA
Position Statement on Genetic Testing 2012 states that 'there should be no compulsion on any person to undertake or refuse any genetic test'. ${ }^{2}$ This consideration should be directly applied to athletes, with all athletes given the right to decline genetic testing, including genetic testing conducted as part of legitimate scientific research. The decision to decline genetic testing should have no impact on an athlete's position within a particular team or sporting organisation nor on their likelihood of selection to an elite sport training programme. Genetic testing in relation to injury risk should not be conducted on athletes until they are able to fully understand the issues relating to genetic testing. In sport, genetic testing is targeted at assessing the risk of injury rather than the risk of a serious condition. Genetic testing in sport, therefore, should not be offered to athletes under the age of 18 years.

Given that the desired outcome of genetic testing for predisposition to injury is appropriate modification of training to mitigate the injury risk, it is likely that the genetic information will be relevant to trainers and coaches. Personnel who may desire access to genetic information may include, but are not limited to, the athlete's coach, physical therapist and strength and conditioning trainer. It is essential that clear policy guidelines are communicated to the athlete and relevant staff in relation to who may access genetic information. Construction and dissemination of clear policy guidelines informing the process of genetic testing should occur prior to any testing taking place. These guidelines must stipulate who can have access to the genetic information and how that information can be used Genetic information should be used for improving injury prevention and health management strategies but should not be used for talent identification or for inclusion or exclusion from high performance programmes.

There are potential risks in implementing a genetic testing regimen in sport without sufficient evidence. Several single nucleotide polymorphisms (SNPs) have been identified as showing suggestive association with increased risk of sportsrelated injuries, based on the case-control, candidate gene approach. $^{52}$ In particular, polymorphisms in the COL5A1, TNC, MMP3 and GDF-5 genes have been suggested to be correlated with Achilles tendon injuries. ${ }^{52}$ 54-56 However, there is currently no evidence to demonstrate that these polymorphisms are relevant in all ethnicities, across both sexes, or that the polymorphisms are predictive of injury risk. Further research is required to examine the relevance of particular SNPs in relation to injury, taking into account the implication of sex and ethnicity, before testing should be offered to athletes.

Many of the direct-to-consumer tests being publicised for use with athletes do not comply with the NHMRC Principles for the translation of 'omics'- based tests from discovery to healthcare. ${ }^{16}$ There is not sufficient evidence that the omics-based tests offered by commercial entities pass the first principle of reproducibility and are therefore unreliable in the results and information being returned to consumers. ${ }^{13}$ Athletes should be discouraged from taking these tests.

Additionally, genetic information may be difficult to interpret for a sports medicine provider who has not had additional training in this area. In 2009, Gibson stated that it can be a challenge for the busy sports medicine practitioner to distil the clinical relevance of association studies' in relation to genetic risk factors for sports injury. ${ }^{57}$ The risk conferred by SNPs differs significantly from the risk conferred from genetic tests for Mendelian or single-gene disorders. For this reason, it is important that practitioners understand the impact of the testing prescribed, and are able to provide counselling to the 
athlete on the risks of genetic testing or to have access to a genetic counsellor should the need arise.

\section{CONCLUSION}

Genomics is a rapidly advancing field across all medical disciplines including sport and exercise medicine. Technological

Box 1 Positions adopted by the Australian Institute of Sport on genetic research and testing of Australian athletes

- Genetic testing for health-related purposes will be ordered by a medical practitioner.

- Genetic testing for health-related purposes will be ordered in conjunction with genetic counselling.

- Should individuals choose to undergo direct-to-consumer genetic testing, they should be discouraged from acting on advice from the commercial company without seeking clarification from a medical practitioner.

- Genetic testing as part of a research project will only occur with the informed, written consent of participants.

- The purposes for which genetic information will be used are clearly articulated to athletes.

- Participants in genetic research will be informed about the possibility of unintentional discoveries that could potentially impact on the participant's health or the health of their relatives.

- Athletes have the right to decline a genetic test.

- There will be no discrimination against athletes who decline genetic testing.

- The management of, and confidentiality pertaining to, genetic testing results will be clearly articulated to the athlete, prior to the participation in research.

- The results of genetic testing will remain confidential unless otherwise explicitly stated.

- Genetic testing for the purpose of research in sport will not be conducted on athletes under the age of 18 years.

- Athletes participating in genetic research have the right to withdraw from research at any time and/or have all of their material and/or results destroyed at any time during the process of testing or research.

- Athletes participating in genetic research have the right to have their material and/or results sent to a third party.

- Genetic testing for research in athletes will involve the least invasive method of sample collection required to deliver the research outcomes.

- Genetic manipulation will not be used for performance enhancement.

- Direct-to-consumer genetic testing in relation to sports performance is strongly discouraged.

- Genetic testing will not be used to include or exclude athletes from a high-performance programme.

- Genetic testing will not be used as a method of talent identification.

- Directing evidence-based interventions to reduce injury and improve health is a legitimate and valid use of genetic information.

- Clear guidelines must define the dissemination of genetic information before a research study or testing regimen is started. advancements and cost reductions have seen genetic research and genetic testing become more accessible to a range of sporting organisations and individuals. The AIS is committed to staying abreast of the latest developments in science and technology without compromising the integrity of sport. The AIS will maintain a clear and unequivocal focus on athlete safety and well-being. This position statement defines the ethical framework within which genetic testing and genetic research will be conducted in Australian sport (box 1).

\section{Twitter: @DrDavid_Hughes}

Acknowledgements The authors wish to acknowledge the Collaborative Research Network for Advancing Exercise and Sports Science (https://bond.edu.au/researchers/ research-strengths/university-research-centres/crn-advancing-exercise-sports-science) and Dr Silvia Manzanero for assistance with preparation of the manuscript.

Contributors NV was responsible for the planning, conduct and reporting of the information within the manuscript. PAF was involved in the planning and review of the manuscript. MAB was involved in the planning and review of the manuscript. DH was involved in the planning, conduct and reporting of the information within the manuscript. DH has the authority to endorse this position statement on behalf of the AIS Department of Sports Medicine.

Funding Funded by the Australian Government and the Collaborative Research Network for Advancing Exercise and Sports Science.

Competing interests None declared.

Provenance and peer review Not commissioned; externally peer reviewed.

Open Access This is an Open Access article distributed in accordance with the Creative Commons Attribution Non Commercial (CC BY-NC 4.0) license, which permits others to distribute, remix, adapt, build upon this work non-commercially, and license their derivative works on different terms, provided the original work is properly cited and the use is non-commercial. See: http://creativecommons.org/ licenses/by-nc/4.0/

\section{REFERENCES}

1 Hayden EC. Technology: The \$1,000 genome. Nature 2014;507:294-5.

2 Australian Medical Association. Position Statement on Genetic Testing. 2012 https://ama.com.au/system/tdf/documents/Position_Statement_on_Genetic_Testing 2012.pdf?file $=1 \&$ type $=$ node\&id $=40669$. Accessed November 2016 .

3 Middleton A, Patch C, Wiggins J, et al. Position statement on opportunistic genomic screening from the Association of Genetic Nurses and Counsellors (UK and Ireland). Eur J Hum Genet 2014;22:955-6.

4 Green ED, Guyer MS, Institute NHGR. Charting a course for genomic medicine from base pairs to bedside. Nature 2011;470:204-13.

5 Moorhead G. Developing An SMA Position on Genetic Testing. Sport Health $2009 ; 27: 2$

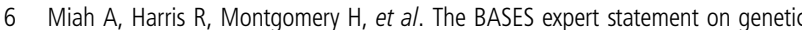
research and testing in sport and exercise science. 2012. http://www.bases.org.uk/ write/Images/williams14-15.pdf. Accessed November 2016.

7 Human Genetics Society of Australasia. Position Statement Genetic Testing and Sports Performance. 2012. https://www.hgsa.org.au/documents/item/19. Accessed November 2016

8 Sheehan NJ. The ramifications of HLA-B27. J R Soc Med 2004;97:10-14.

9 Jouanolle AM, Fergelot $P$, Gandon $G$, et al. A candidate gene for hemochromatosis: frequency of the C282Y and H63D mutations. Hum Genet 1997;100:544-7.

10 King M-C, Marks JH, Mandell JB. Breast and ovarian cancer risks due to inherited mutations in BRCA1 and BRCA2. Science 2003;302:643-6.

11 Cañadas V, Vilacosta I, Bruna I, et al. Marfan syndrome. Part 1: pathophysiology and diagnosis. Nat Rev Cardiol 2010;7:256-65.

12 Ramachandra CJ, Mehta A, Guo KWQ, et al. Molecular pathogenesis of Marfan syndrome. Int J Cardiol 2015;187:585-91.

13 Webborn N, Williams A, McNamee M, et al. Direct-to-consumer genetic testing for predicting sports performance and talent identification: consensus statement. Br J Sports Med 2015;49:1486-91.

14 Borry $P$, van Hellemondt RE, Sprumont $D$, et al. Legislation on direct-to-consumer genetic testing in seven European countries. Eur J Hum Genet 2012;20:715-21.

15 Kutz G. Direct-to-Consumer genetic tests: misleading test results are further complicated by deceptive marketing and other questionable practices: congressional testimony. DIANE Publishing, 2010.

16 National Health and Medical Research Council. Principles for the translation of 'omics'-based tests from discovery to health care. 2015. https://www.nhmrc.gov. au/_files_nhmrc/publications/attachments/g10_principles_translation_omics_based_ tests_a_150421_0.pdf. Accessed November 2016. 
17 National Health and Medical Research Council. National Statement on Ethical Conduct in Human Research. 2007. (Updated May 2015). https://www.nhmrc.gov. au/printpdf/book/export/html/51613. Accessed November 2016.

18 McGuire AL, Beskow LM. Informed consent in genomics and genetic research. Annu Rev Genomics Hum Genet 2010;11:361.

19 U.S. Food and Drug Administration. Optimizing FDA's regulatory oversight of next generation sequencing diagnostic tests-preliminary discussion paper. 2015. http:// www.fda.gov/downloads/MedicalDevices/NewsEvents/WorkshopsConferences/ UCM427869.pdf. (accessed November 2016).

20 Stavropoulos J, Shago $\mathrm{M}$, Bruyere $\mathrm{H}$, et al. CCMG guidelines for genomic microarray testing. Analysis 2010;6:6

21 Johnstone E, Doyal L, Grubbs A. Human tissue and biological samples for use in research: operational and ethical guidelines. London, UK: Medical Research Council, 2001. https://www.mrc.ac.uk/publications/browse/human-tissue-and-biologicalsamples-for-use-in-research/. (accessed November 2016).

22 Egalite N, Groisman IJ, Godard B. Genetic counseling practice in next generation sequencing research: implications for the ethical oversight of the informed consent process. J Genet Couns 2014;23:661-70.

23 Reilly PR, Boshar MR, Holtzman SH. Ethical issues in genetic research: disclosure and informed consent. Nat Genet 1997;15:16-20.

24 Morgenstern J, Hegele RA, Nisker J. Simple genetics language as source of miscommunication between genetics researchers and potential research participants in informed consent documents. Public Underst Sci 2015;24:751-66.

25 Green RC, Berg JS, Grody WW, et al. ACMG recommendations for reporting of incidental findings in clinical exome and genome sequencing. Genet Med 2013;15:565-74.

26 Antonini Philippe R, Sagar SS, Huguet $S$, et al. From teacher to friend: the evolving nature of the coach-athlete relationship. Int J Sport Psychol 2011;42:1-23.

27 Miller PS, Kerr GA. Conceptualizing excellence: past, present, and future. J App/ Sport Psychol 2002;14:140-53.

28 Botkin JR, Belmont JW, Berg JS, et al. Points to consider: ethical, legal, and psychosocial implications of genetic testing in children and adolescents. Am J Hum Genet 2015;97:6-21.

29 Ginn $\mathrm{SL}$, Alexander IE, Edelstein $\mathrm{ML}$, et al. Gene therapy clinical trials worldwide to 2012-an update. J Gene Med 2013;15:65-77.

30 Fillip F. Is science killing sport: gene therapy and its possible abuse in doping. EMBO Rep 2007;5:433-5.

31 World Anti-Doping Agency. The World Anti-Doping Code: the 2015 Prohibited List International Standard. 2015. http://www.fivb.org/EN/Medical/Document/WADAProhibited-List-2015-EN.pdf. (accessed November 2016).

32 Gayagay G, Yu B, Hambly B, et al. Elite endurance athletes and the ACE I allelethe role of genes in athletic performance. Hum Genet 1998;103:48-50.

33 Montgomery $\mathrm{H}$, Marshall $\mathrm{R}$, Hemingway $\mathrm{H}$, et al. Human gene for physical performance. Nature 1998;393:221-2.

34 Yang N, MacArthur DG, Gulbin JP, et al. ACTN3 genotype is associated with human elite athletic performance. Am J Hum Genet 2003;73:627-31.

35 Eynon N, Hanson ED, Lucia A, et al. Genes for elite power and sprint performance: ACTN3 leads the way. Sports Med 2013;43:803-17.

36 Ma F, Yang Y, Li X, et al. The association of sport performance with ACE and ACTN3 genetic polymorphisms: a systematic review and meta-analysis. PLOS ONE 2013:8:e54685.

37 Guilherme JPLF, Tritto ACC, North KN, et al. Genetics and sport performance: current challenges and directions to the future. Revista Brasileira de Educação Física e Esporte 2014;28:177-93.
38 Pitsiladis $Y$, Wang $G$, Wolfarth $B$, et al. Genomics of elite sporting performance: what little we know and necessary advances. Br J Sports Med 2013;47:550-5.

39 Loland S. Against genetic tests for athletic talent: the primacy of the phenotype. Sports Med 2015:45:1229-33.

40 Australian Government Federal Register of Legislation. Therapeutic Goods (Excluded purposes) Specification. 2010. https://www.legislation.gov.au/Details/F2010L01889 (accessed November 2016).

41 Essentially Yours: The Protection of Human Genetic Information in Australia Australian Law Reform Commission, 2003. Available at: http://www.alrc.gov.au/ publications/report-96. Accessed: November 2016.

42 Junge A, Dvorak J. Injury surveillance in the world football tournaments 19982012. Br J Sports Med 2013;47:782-8.

43 Engebretsen L, Soligard T, Steffen K, et al. Sports injuries and illnesses during the London Summer Olympic Games 2012. Br J Sports Med 2013;47:407-14.

44 van Gent BR, Siem DD, van Middelkoop M, et al. Incidence and determinants of lower extremity running injuries in long distance runners: a systematic review. $\mathrm{Br}$ J Sports Med 2007:41:469-80; discussion 480.

45 Tonoli C, Cumps E, Aerts I, et al. Incidence, risk factors and prevention of running related injuries in long-distance running: a systematic review Injury, location and type. Sport en Geneeskunde 2010;43:12-18.

46 Palmer-Green D, Fuller $C$, Jaques $R$, et al. The Injury/llness Performance Project (IIPP): a novel epidemiological approach for recording the consequences of sports injuries and illnesses. J Sports Med 2013;2013:523974.

47 Raysmith B, Drew MK. Performance success or failure is explained by weeks lost to injury and illness in elite Australian track and field athletes: a 5-year prospective study. J Sci Med Sport 2016;19:778-83.

48 Schwellnus M. Genetic biomarkers and exercise-related injuries: current clinical applications? Br J Sports Med 2013:47:530-2.

49 Friedman E, Moran DS, Ben-Avraham D, et al. Novel candidate genes putatively involved in stress fracture predisposition detected by whole-exome sequencing. Genet Res 2014;96:e004.

50 Varley I, Hughes DC, Greeves JP, et al. RANK/RANKL/OPG pathway: genetic associations with stress fracture period prevalence in elite athletes. Bone 2015;71:131-6

51 September A, Posthumus M, Collins M. Application of genomics in the prevention treatment and management of Achilles tendinopathy and anterior cruciate ligament ruptures. Recent Pat DNA Gene Seq 2012;6:216-23.

52 Raleigh SM, Collins M. Gene variants that predispose to Achilles tendon injuries: an update on recent advances. INTECH Open Access Publisher, 2012.

53 Posthumus $M$, September AV, Keegan $M$, et al. Genetic risk factors for anterior cruciate ligament ruptures: COL1A1 gene variant. Br J Sports Med 2009:43:352-6.

54 Posthumus $\mathrm{M}$, Collins $\mathrm{M}$, Cook J, et al. Components of the transforming growth factor- $\beta$ family and the pathogenesis of human Achilles tendon pathology-a genetic association study. Rheumatology 2010;49:2090-7.

55 Raleigh SM, Van der Merwe L, Ribbans WJ, et al. Variants within the MMP3 gene are associated with Achilles tendinopathy: possible interaction with the COL5A1 gene. Br J Sports Med 2009;43:514-20.

56 September AV, Cook J, Handley CJ, et al. Variants within the COL5A1 gene are associated with Achilles tendinopathy in two populations. Br J Sports Med 2009:43:357-65.

57 Gibson WT. Genetic association studies for complex traits: relevance for the sports medicine practitioner. Br J Sports Med 2009;43:314-16. 